\title{
Pragmatic Competence of Iranian EFL Learners in the Light of Refusal Speech Act
}

\author{
Bibi Malihe Vamagh Shahi \\ Department of English Language and Literature, Ferdowsi University of Mashhad, Mashhad, Iran
}

\begin{abstract}
In order to communicate accurately and fluently, learners need to know how to produce different speech acts inside and outside the classroom context. Refusal speech act is complicated, and performing refusals successfully needs a higher level of pragmatic competence (Eslami, 2010). This study is done in order to analyze refusal speech act and its responses among Iranian EFL learners. The participants of this study are 120 advanced Iranian EFL learners. These learners are provided with scenarios so that they are exposed to situations where they should both refuse and respond to refusals. The first phase of this paper includes the analysis of refusal strategies. The second phase of the paper deals with refusal responses. It was revealed that female participants are more inclined to use indirect strategies as related to refusals and male participants are more inclined to use direct strategies. For refusal responses, male learners used reinforcing micro functions while female learners used accepting micro functions more frequently. The results of this study contribute to pragmatic instruction in a way to help learners interpret and realize this speech act successfully. I will also investigate possible cross-cultural miscommunication, which its occurrence is also acknowledged in previous research studies (Shishavan \& Sharifian, 2016).
\end{abstract}

Index Terms - cross-cultural miscommunication, EFL learners, pragmatic instruction, refusal speech act

\section{INTRODUCTION}

Social language abilities are fundamental segments of fruitful interaction with others. As such, individuals need to realize what to say, how to say it, their non-verbal communication and regardless of whether it is fitting to the given circumstance (Brown, 2007). The utilization of language in friendly settings and the manners by which individuals deliver and understand implications through language has been of the primary worry of language researchers which drove them to think of the idea of Pragmatics.

Pragmatics has different implications relying upon the unique situation; be that as it may, it has a more particular importance in applied phonetics. Morris, in his semiotics, in 1971 first proposed the possibility of pragmatics as chiefly the investigation of the connection between the signs and their mediators or between the language and the people who utilize it in friendly settings. As per Yule (2006), pragmatics is the investigation of significance as passed on by a speaker/essayist and comprehended by an audience/peruser. In fact, it endeavors to examine the implying that the speaker/essayist needs to co-build alongside the audience/peruser inside a particular social setting with thinking about the social requirements (Stadler, 2011). Close by the investigation of pragmatics, there seems another field called Interlanguage Pragmatics (ILP). To be more exact, ILP endeavors to research non-local speakers' development and cognizance of the even minded highlights of the objective language accepting the investigation of implicatures, graciousness procedures, presuppositions and speech acts. Speech acts are actions accomplished by expressions like providing request, promising, rejecting, grumbling, mentioning, and so forth They assume an observable part in second language (L2) correspondence, and are workable and learnable, in this way, they are among the most completely examined regions in pragmatics.

Not exclusively does the setting where the expression is delivered assume an incredible part in translation of a message, yet in addition the way of life of members partaking in the act of correspondence can assume a recognizable part in passing on the importance. As Golato (2003) states, the correspondence created isn't made in a social vacuum. In view of the chief point of pragmatics in genuine use, for example the utilization of language in various social and social settings, the students ought to know about the determination and use of the right speech act procedure assuming they need to keep away from diverse false impressions. At the point when speech acts are played out, the students should know about the "normal practices" (e.g., realizing the ideal opportunity to ask your supervisor for an advancement), "social thinking", which can be characterized as why the speech acts are created in that manner, and "information" about the result of having expressed that speech act in that specific culture. Subsequently, the students can profit with knowing about the accompanying factors assuming they need to have fruitful correspondence in the objective language: (1) the objective language culture, (2) the age and sex of the speaker as against the listener(s), (3) their social class and callings, and (4) the societal position and jobs of individuals associated with the interaction (Jalilimehr et al., 2012).

As referenced before, a fruitful interaction requires the conversationalists' determination of the kind of circumstance (where offering, promising, or mentioning, and so forth is required) and choice on appropriate action to be performed is called speech acts. Likewise, just some specific ways are satisfactory for a circumstance and speech act for having a 
successful correspondence. Most speech acts are responsible to have ordinary and regular examples for speakers of any language (Cutting, 2002). Also, the fact that to whom the speaker is passing on the message; the conversationalists' general power and social position, is of boss factors which ought not to be overlooked in any friendly correspondence.

Correspondence, routinely, is assumed as just communicating one's thoughts. By and by, this conviction ought to be considered inside and out to arrive at an unmistakable discernment in the act of correspondence. For example, the act of saying 'sorry' is undoubtedly the act of verbally communicating lament for (not) accomplishing something and conceding the fact that what the speaker has (not) done might have caused the listener some damage. A conciliatory sentiment is open because of the statement of a specific mentality stowed away in the act, for this situation lament. The correspondence; notwithstanding, as Austin (1962) announces, succeeds in case it is seen and perceived as proposed. Consequently, in a fruitful act of conciliatory sentiment, for example, the recipient ought to recognize the speaker's expectation for communicating lament for some deed or exclusion. Additionally, if the speaker picks his words so that the recipient can know about his informative goal, the ideal open achievement is certainly acquired. Thus, with the end goal of expression of remorse, articulating "oh no" can be sufficient to tell the listener that in fact the speaker needs to show lament.

As talked about above, when an expression is created, not exclusively might want the speaker to communicate his/her aim by picking a particular act, however he likewise endeavors to deliver some outcome on the audience. Our speech act determination of words (jargon) can cloud this fact, however. By articulating conciliatory sentiment, for instance, one might expect not only to communicate lament yet in addition to request absolution; albeit, one expression is the presentation of an act of the two sorts. As a conciliatory sentiment, the informative reason will be satisfied in case it is taken as communicating lament for the deed; while, the act of looking for absolution succeeds in case pardoning is in this manner got.

Speech acts, as expressed prior, have three incorporated levels, specifically locutionary, illocutionary and perlocutionary. In spite of this, they are segregated for the most part by their illocutionary type, for example, mentioning, promising and saying 'sorry' which are in fact recognized by the kind of disposition communicated. In any case, the fact stays that speech acts for the most part have some ulterior reason the perlocutionary act which should be accomplished in any fruitful correspondence. By perlocutionary act it is implied that the speaker is attempting to get the listener to have the relating demeanor or to act in an unmistakable manner. A solicitation, for instance, communicates the speaker's eagerness towards the recipient to do something specific and in fact looks for the recipient's goal to actually do that thing. Notwithstanding, with regards to arranging the speech acts, they are for the most part thought to be founded on their illocutionary acts as opposed with the impact they can have on the listener. Consequently, in regards to all the previously mentioned thoughts regarding speech acts and the goals conveyed in any act, four unmistakable kinds of speech acts are classified as: constatives, mandates, commissives and affirmations. This terminology, which is a nitty gritty scientific classification of speech acts, was applied by Cutting (2002) in which each kind of illocutionary act is distinguished by the sort of mentality communicated in that speech act.

Consequently, this paper will give a foundation to the thought of speech act, especially the refusal speech act based on which this examination is completed, notwithstanding the idea of Face and the social factors that impact any suitable expression of speech act. Then, at that point, it will express the issue that is meant to be fixed by doing this examination and furthermore it will present importance and motivation behind the current investigation. From that point onward, the exploration questions tended to by this examination and a few speculations will be introduced.

Specialists accept that speech acts are outstanding amongst other methods of contemplating correspondence styles because of their utilization of minor practically identical units of talk. Subsequently, examination of this sort can add to comprehension of human's semantic presentation and tracking down the essential examples of a speech act. Likewise, the idea of sex is of interest among sociolinguistic researchers. At the end of the day, the assortment and differentiation which might exist among people in applying certain procedures for a particular speech act have stirred the interest of numerous analysts. The aftereffect of such investigations can profit the language educators, first, to perceive any conceivable sociolinguistic contrasts between the sexual orientations, second, to see the sexes' eagerness in choosing explicit methodologies for a speech act, lastly, to give the students the necessary etymological information for playing out the very speech act.

Additionally, speech acts, among them the refusal speech acts in light of their high incessant nature, are essential pieces of language without which a speaker misses nothing to joke about of a fruitful correspondence. Thusly, experiences can be conceded to the language instructors to be definitely aware of this fact and the outcomes can help them not restrict themselves in showing speech act uses and techniques just to higher capability understudies. To this end, to have more successful job in classes, the instructors ought to give clear criticism of how students perform (in regards to a speech act) at different levels and what their propensity towards the speech act procedure resembles. The aftereffects of this examination are relied upon to reveal insight into previously mentioned focuses and help language practitioners have clear comprehension of their students concerning their sex and capability contrasts.

\section{REVIEW OF THE LITERATURE}

Pragmatics places accentuation on the importance in discussions among conversationalists. All in all, a student with full syntactic skill may not be even-mindedly capable as well. Students might create right syntactic sentences in 
discussions which are logically improper. Along these lines, such breakdowns might frustrate the correspondence among conversationalists which is called 'down to earth disappointment'. One of the significant factors of even minded disappointment lies in the fact that students move speech act methodologies from their local language (Ellis, 2008). The subsequent one identifies with input. In spite of the fact that it is important for students to get a lot of contribution from the climate, English reading material might have issues to introduce activities which target sober minded ability (Kasper, 1984).

Pragmatics is the investigation of language utilized in legitimate discussions which mirrors the relationship among sentences, settings, and circumstances. Pragmatics has not an obvious definition (Ellis, 2008). As Kasper (1984) referenced, pragmatics thinks about etymological highlights according to clients of that language. One of the hidden subjects in pragmatics is speech act. The hypothesis of speech acts is grown chiefly by certain scientists. The focal suspicion in the hypothesis of speech act is that the negligible unit of correspondence isn't a sentence or different articulations but instead language act. In another term, human language can be seen as actions. People perform things by saying various types of language acts like refusals, solicitations, guarantees and so forth. Austin (1962, p. 67) examined speech acts according to the accompanying viewpoint: "to consider from the beginning the number of faculties there are in which to say something is to accomplish something, or in saying something we accomplish something and even by saying something we accomplish something." According to his view, any expression is made out of the accompanying acts: the locutionary act (the actual words the speaker is saying), the illocutionary act (the expectation of the speaker) and the perlocutionary act (the impact of expression on the listener).

Language learning doesn't occur in a vacuum. Thus, the nature of interactions ought to be broke down as per common requirements which exist among questioners. Along these lines, Brown (2007) squabbled over the biology of language which considers the ecological factors of realizing which thusly put accentuation on the language use. The thought prospers with what Verschueren (1999) schematized as natural points of view of language.

In their model, Brown (2007) alluded to four factors: Microsystem, Mesosystem, Ecosystem, and Macrosystem. Microsystem is the nearest ecological layer influencing the student which accepts guardians, instructors, kin and companions. Macrosystem, which is set at the furthest layer, considers the whole culture of the general public. These biological viewpoints which are addressed by Williams and Burden are not unlike the construction of an onion stressing that people have interactions with social and cultural highlights and the student is set at the focal point of a mind boggling structure. Hence, people might have various styles and systems when talking together since they are from various societal position and there are, obviously, power relations which are probably going to impact the nature of talk among questioners. With respect to the speech act, the shows of the general public are solid indicators of how people perform various acts according to other people.

Customarily, under the rubric of Grammar Translation Method (GTM), language was viewed as a bunch of abstract punctuation rules and arrangements of jargon to remember (Richards and Rodgers, 2001). The focal worry of unknown dialect study was to examine language in its own purpose. In this time, there was no attempt to think about the biology of language which accounts the speech local area also. With the coming of Communicative Language Teaching (CLT), notwithstanding, the consideration transformed from the investigation of language in a vacuum to explore the actual utilization of language in an intentional setting wherein the open ability was the focal concern (Brown, 2007). With the incredible spotlight on phonetic variety and fittingness of the language being utilized, language went to a riddle, addressing every one of which needs to see the issue with various glasses. It was no more the language that made a difference the most. Each language has clients. It is the clients of a language, among different factors, that has given the language its confounded nature. For example, how it is feasible to characterize great or how much commitment is behind an absolute necessity, has to realize the two conversationalists conveying the words just as the situational factors. At the point when the focal point of consideration moved for language use and when specialists gave a valiant effort to research sort of changeability found in student language (Ellis, 2008), information on pragmatics acquired significance.

Pragmatics has not a fixed definition (Ellis, 2008); be that as it may, the overall idea of pragmatics identifies with the thought of semantic highlights according to clients of the language. Richards and Schmidt (2002) examined pragmatics as "the investigation of the utilization of language in correspondence, especially the connections among sentences and the unique circumstances and circumstances in which they are utilized" (p. 412). As per Ishihara and Cohen (2010, p. 3), a logically solid correspondence in L2 relies upon the accompanying factors:

(1) our proficiency in that L2 and possibly in other (especially related) languages, (2) our age, gender, occupation, social status, and experience in the relevant L2-speaking communities, and (3) our previous experiences with pragmatically competent L2 speakers and our multilingual/multicultural experiences in general.

Communication, conventionally, is supposed as merely expressing oneself. Nevertheless, this belief should be considered in depth in order to reach a clear perception in the act of communication. For instance, the act of apologizing is indeed the act of verbally expressing regret for (not) doing something and admitting the fact that what the speaker has (not) done might have caused the hearer some harm. An apology is communicative due to the expression of a certain attitude hidden in the act, in this case regret. The communication; however, succeeds if it is perceived and understood as intended. Thus, in a successful act of apology, for instance, the addressee should identify the speaker's intention for expressing regret for some deed or omission. Moreover, if the speaker chooses his words in such a way that the 
addressee can be aware of his communicative intention, the desired communicative success is definitely gained. So, for the purpose of apology, uttering "oops" can be enough to let the hearer know that in fact the speaker wants to show regret.

As discussed above, when an utterance is produced, not only would like the speaker to express his/her intention by choosing a specific act, but he also attempts to produce some effect on the listener. Our speech act selection of words (vocabulary) can obscure this fact, though. By uttering apology, for example, one may intend not merely to express regret but also to ask for forgiveness; although, one utterance is the performance of an act of both types. As an apology, the communicative purpose will be fulfilled if it is taken as expressing regret for the deed; while, the act of seeking forgiveness succeeds if forgiveness is thereby obtained.

\section{RESULTS}

\section{EFL Learners' Refusal Utterances}

During this phase of the study, refusal utterances are investigated using the four eliciting tools. Refusal utterances are investigated with regard to being direct and indirect. Generally speaking, refusals have the primary macro function of being indirect in all four eliciting acts. However, with regard to micro functions the frequencies are different. The frequency table of each eliciting tool is manifested in the following parts. It was found out that refusals to requests have elicited more refusals than any other eliciting tool as it is related to EFL learners. It means that it is more likely that learners would react to requests more than other eliciting tools.

Among the macro levels, it is clear that most EFL learners were inclined towards indirect strategies. As related to micro strategies, it was found out that male EFL learners had a tendency toward excuse $(n=15)$ but female learners were more inclined towards performative verbs $(n=23)$. Then, female learners try to use the direct macro function as the primary response but male learners used indirect macro function. Table 1 reveals the distribution of frequencies in refusals of requests in different genders:

TABLE 1

DIRECT AND INDIRECT STRATEGIES OF REFUSALS TO REQUESTS

\begin{tabular}{|c|c|c|c|c|c|}
\hline \multirow[t]{2}{*}{ Macro Level } & & \multirow[t]{2}{*}{ Micro Strategies } & \multicolumn{2}{|c|}{ Frequency } & \multirow[t]{2}{*}{ Total } \\
\hline & & & Male & Female & \\
\hline \multirow[t]{24}{*}{ Direct Strategies } & & Performative verbs & 12 & 23 & 35 \\
\hline & & Non-performative statements & 5 & 7 & 12 \\
\hline & \multirow{22}{*}{ 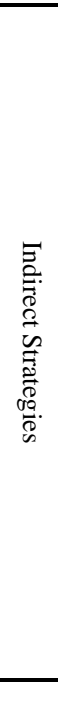 } & Regret & 4 & 9 & 13 \\
\hline & & Wish & 8 & 3 & 12 \\
\hline & & Excuse, reason, and explanation & 15 & 5 & 20 \\
\hline & & Alternative & 4 & 9 & 13 \\
\hline & & Set condition & 3 & 6 & 9 \\
\hline & & Promise of acceptance & 7 & 8 & 15 \\
\hline & & St. principle & 9 & 12 & 21 \\
\hline & & Threat or St. consequence & 1 & 5 & 6 \\
\hline & & Guilt trip & 6 & 11 & 17 \\
\hline & & Criticism & 7 & 11 & 18 \\
\hline & & Request & 5 & 4 & 9 \\
\hline & & Off the hook & 1 & 2 & 3 \\
\hline & & Self-defense & 4 & 4 & 8 \\
\hline & & Unspecific reply & 5 & 3 & 8 \\
\hline & & Lack of enthusiasm & 2 & 4 & 6 \\
\hline & & Non-verbal avoidance & 2 & 3 & 5 \\
\hline & & Topic switch & 1 & 5 & 6 \\
\hline & & Joke & 3 & 1 & 4 \\
\hline & & Repetition & 2 & 1 & 3 \\
\hline & & Postponement & 4 & 3 & 7 \\
\hline & & Hedge & 2 & 5 & 7 \\
\hline & & Total & 113 & 144 & 257 \\
\hline
\end{tabular}

As it is revealed in Table 1, male EFL learners used threat, off the hook, and topic switch with the least frequency. Among female learners, joke and repetition were the least used semantic formula. Overall, it was female learners who used more refusals to requests. The data showed that most women tried to refuse a request even by producing a combined strategy to show the strength of the refusal. Another interesting issue is that females used micro functions which were more accepted in the society, for instance, girls used less jokes than males.

As it is related to refusals which are gathered through suggestions, it was found out that both men and women had a tendency toward indirect macro level. Among micro levels, male EFL learners used non-performative statements most $(n=22)$ but among female participants it was non-performative verbs $(n=14)$ which outweigh other micro functions. Then the primary response type for both men and women is direct macro level. Table 2 reveals summary of results: 
TABLE 2

DiRECT AND INDIRECT STRATEGIES OF REFUSALS TO SUGGESTION

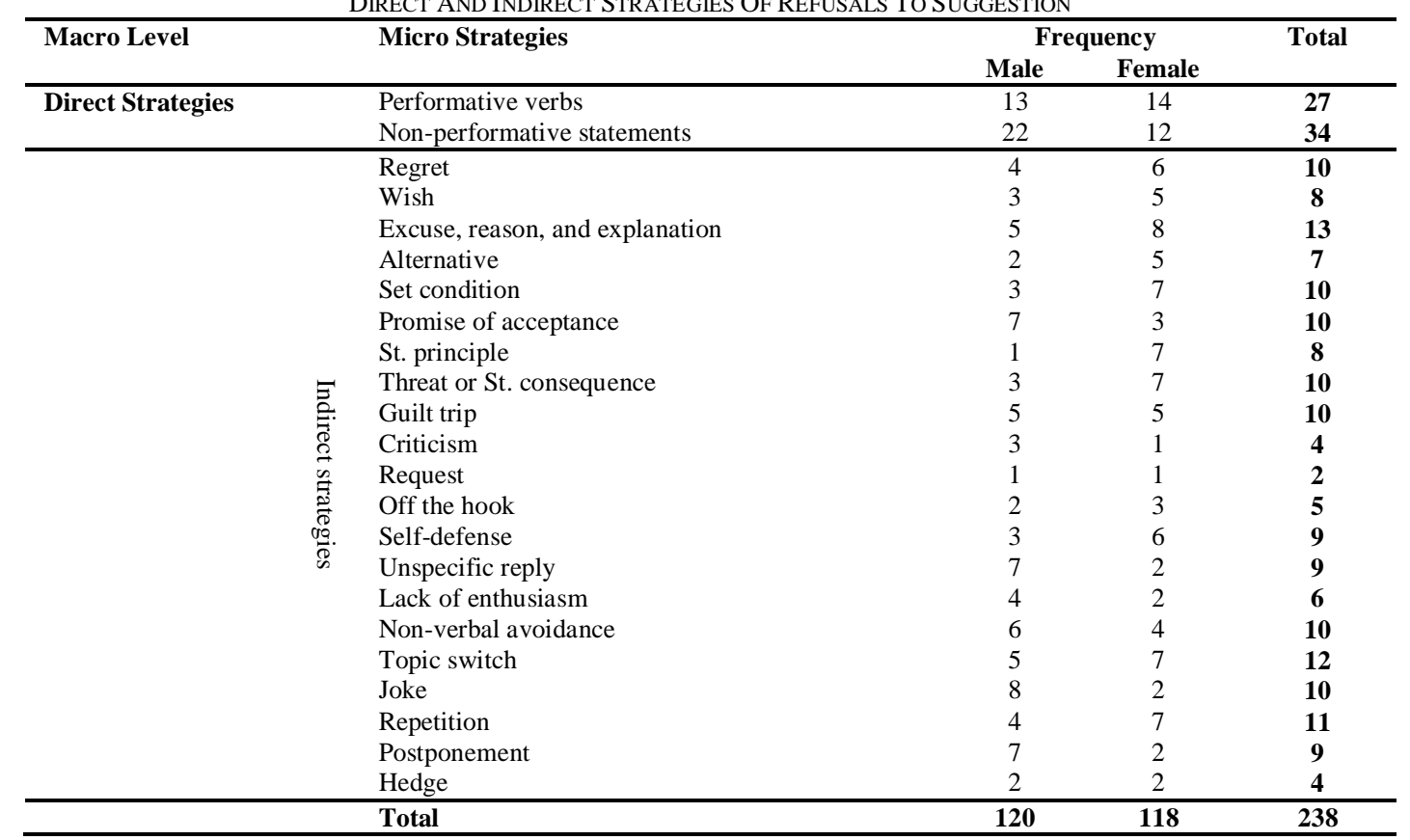

Male EFL learners used statement of principle and request as the least used micro functions while for female learners it was criticism and request which were observed with the least frequencies. All in all, men used more refusals in this type of eliciting act. Men produced 120 refusals but women produced 118 refusals. In this type of refusals as well, it was observed that females are affected by the Iranian concept of adab (courtesy). For instance, female learners used less jokes that men.

For refusals to offers, men and women were inclined to use indirect strategies. That is to say, the frequency of indirect micro functions was higher with comparison to direct macro function. For male EFL learners, the most used micro function is joke $(n=9)$ and for women the most used macro function is non-performative statements $(n=14)$. Therefore, for a more clear investigation, females' primary response type would be a direct one but for male learners it is the indirect strategies which outweigh. Another important feature of the following table is that as it is related to 'lack of enthusiasm', female learners significantly used more refusals than male learners. It is again part of women's psychology. It is generally believed that women tend to show that they have more interest towards communication and establishing a conversation (Ishihara \& Cohen, 2010). However, the results of this study showed a different pattern with regard to refusals to offers. Table 3 reveals summary of results: 
TABLE 3

DIRECT AND INDIRECT STRATEGIES OF REFUSALS TO OFFERS

\begin{tabular}{|c|c|c|c|c|c|}
\hline \multirow[t]{2}{*}{ Macro Level } & & \multirow[t]{2}{*}{ Micro Strategies } & \multicolumn{2}{|c|}{ Frequency } & \multirow[t]{2}{*}{ Total } \\
\hline & & & Male & Female & \\
\hline \multirow{2}{*}{\multicolumn{2}{|c|}{ Direct Strategies }} & Performative verbs & 7 & 9 & 16 \\
\hline & & Non-performative statements & 6 & 14 & 20 \\
\hline & \multirow{22}{*}{ 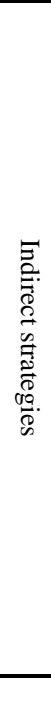 } & Regret & 8 & 3 & 11 \\
\hline & & Wish & 3 & 3 & 6 \\
\hline & & Excuse, reason, and explanation & 1 & 1 & 2 \\
\hline & & Alternative & 1 & 1 & 2 \\
\hline & & Set condition & 6 & 3 & 9 \\
\hline & & Promise of acceptance & 2 & 7 & 9 \\
\hline & & St. principle & 7 & 3 & 10 \\
\hline & & Threat or St. consequence & 5 & 5 & 10 \\
\hline & & Guilt trip & 3 & 3 & 6 \\
\hline & & Criticism & 1 & 3 & 4 \\
\hline & & Request & 6 & 9 & 15 \\
\hline & & Off the hook & 7 & 8 & 15 \\
\hline & & Self-defense & 3 & 9 & 12 \\
\hline & & Unspecific reply & 3 & 5 & 8 \\
\hline & & Lack of enthusiasm & 2 & 11 & 13 \\
\hline & & Non-verbal avoidance & 1 & 3 & 4 \\
\hline & & Topic switch & 4 & 8 & 12 \\
\hline & & Joke & 9 & 1 & 10 \\
\hline & & Repetition & 3 & 5 & 8 \\
\hline & & Postponement & 3 & 3 & 6 \\
\hline & & Hedge & 4 & 6 & 10 \\
\hline & & Total & 95 & 123 & 218 \\
\hline
\end{tabular}

Among male EFL learners, alternative comments, criticism, and non-verbal avoidance were observed with the least frequency. It means that male EFL learners did not have inclination to use these micro functions. However, among female EFL learners, functions such as excuse, alternative comments, and joke were used the least. Women used more refusals than men as it is related to refusals to offers. That is to say, offers would elicit more refusals from female learners than male ones.

As it is related to refusals to invitations, it should be mentioned that the most dominant macro function is direct. Both male and female EFL learners used direct strategies as the dominant way to refuse invitations. Both male and female EFL learners used performative verbs $(n=12,22$, respectively) to refuse invitations. Therefore, the primary function of refusals for invitation is direct. Table 4 reveals summary of results:

TABLE 4

DIRECT AND INDIRECT STRATEGIES OF REFUSALS TO INVITATIONS

\begin{tabular}{|c|c|c|c|c|c|}
\hline \multirow[t]{2}{*}{ Macro Level } & & \multirow[t]{2}{*}{ Micro Strategies } & \multicolumn{2}{|c|}{ Frequency } & \multirow[t]{2}{*}{ Total } \\
\hline & & & Male & Female & \\
\hline \multirow{2}{*}{\multicolumn{2}{|c|}{ Direct Strategies }} & Performative verbs & 12 & 22 & 34 \\
\hline & & Non-performative statements & 6 & 9 & 15 \\
\hline & \multirow{22}{*}{ 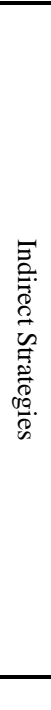 } & Regret & 4 & 4 & 8 \\
\hline & & Wish & 6 & 8 & 14 \\
\hline & & Excuse, reason, and explanation & 3 & 9 & 12 \\
\hline & & Alternative & 6 & 8 & 14 \\
\hline & & Set condition & 6 & 1 & 7 \\
\hline & & Promise of acceptance & 3 & 7 & 10 \\
\hline & & St. principle & 2 & 5 & 7 \\
\hline & & Threat or St. consequence & 1 & 3 & 4 \\
\hline & & Guilt trip & 3 & 1 & 4 \\
\hline & & Criticism & 6 & 3 & 9 \\
\hline & & Request & 7 & 6 & 13 \\
\hline & & Off the hook & 4 & 8 & 12 \\
\hline & & Self-defense & 2 & 8 & 10 \\
\hline & & Unspecific reply & 4 & 7 & 11 \\
\hline & & Lack of enthusiasm & 2 & 7 & 9 \\
\hline & & Non-verbal avoidance & 1 & 11 & 12 \\
\hline & & Topic switch & 3 & 7 & 10 \\
\hline & & Joke & 7 & 2 & 9 \\
\hline & & Repetition & 5 & 3 & 8 \\
\hline & & Postponement & 4 & 4 & 8 \\
\hline & & Hedge & 3 & 2 & 5 \\
\hline & & Total & 100 & 145 & 245 \\
\hline
\end{tabular}

As for the similarity of comparison among all the eliciting tools, in refusals to invitations, the least used strategies by men were threat and nonverbal avoidance while for women strategies such as set condition and guilt trip were used the least. Generally speaking, women were more inclined to refuse in situations related to invitation. 
To put it in a nutshell, after rank ordering the frequency of refusal utterances, we found out that female EFL learners $(n=530)$ used more refusals in their utterances than male learners $(n=427)$. Female EFL learners used 530 refusals which are higher than the amount which was observed by male learners. It can be concluded that, as earlier were discussed, women provide more refusals than men among EFL learners. It means that female learners were less concerned with the positive face of the interlocutors. In other words, they were not inclined as being more polite than men. Part of this characteristic comes from the societal factors. Persian culture put women in a specific framework in which women should respect concepts such as adab (courtesy) and sh'an (dignity). Therefore, having been influenced by these features, women try to refuse more since the acceptance of a request or other eliciting acts would be regarded impolite especially when the other interlocutor is a man. Table 5 shows the significance of differences between male and female EFL learners with regard to refusals:

TABLE 5

ANALYSIS OF SIGNIFICANCE OF DIFFERENCES WITH REGARD TO REFUSAL MACRO FUNCTIONS

\begin{tabular}{|c|c|c|c|c|}
\hline Macro Functions & Male & Female & $\mathbf{X}^{2}$ & $\begin{array}{c}\text { Sig. } \\
p<.05\end{array}$ \\
\hline Direct & 83 & 110 & 3.777 & .052 \\
\hline Indirect & 344 & 420 & 7.560 & $.006^{*}$ \\
\hline
\end{tabular}

* Significant at $p$ value of .05

As the previous table showed, the result of Chi-square analysis revealed that there is a significant difference between male and female EFL learners with regard to indirect macro functions of refusal $\left(\mathrm{X}^{2}=7.560\right)$. However, with regard to direct macro function, there is no significance difference $\left(X^{2}=3.777\right)$. Table 6 shows a summary of main results as related to men and women in the study. For a matter of comparison, direct and indirect strategies are separated.

TABLE 6

OVERALL GENDER DIFFERENCES BETWEEN EFL LEARNERS WITH REGARD TO REFUSALS

\begin{tabular}{|c|c|c|c|c|c|}
\hline \multirow[t]{2}{*}{ Macro Level } & & \multirow[t]{2}{*}{ Micro Strategies } & \multicolumn{2}{|c|}{ Frequency } & \multirow[t]{2}{*}{ Total } \\
\hline & & & Male & Female & \\
\hline \multirow{24}{*}{ Direct Strategies } & & Performative verbs & 44 & 68 & 112 \\
\hline & & Non-performative statements & 39 & 42 & 81 \\
\hline & \multirow{22}{*}{ 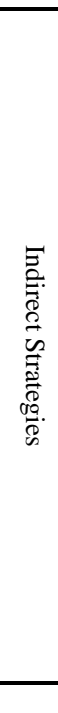 } & Regret & 20 & 22 & 42 \\
\hline & & Wish & 20 & 19 & 39 \\
\hline & & Excuse, reason, and explanation & 10 & 23 & 33 \\
\hline & & Alternative & 13 & 23 & 36 \\
\hline & & Set condition & 18 & 17 & 35 \\
\hline & & Promise of acceptance & 19 & 25 & 44 \\
\hline & & St. principle & 19 & 27 & 46 \\
\hline & & Threat or St. consequence & 24 & 20 & 44 \\
\hline & & Guilt trip & 17 & 20 & 37 \\
\hline & & Criticism & 17 & 18 & 35 \\
\hline & & Request & 19 & 20 & 39 \\
\hline & & Off the hook & 14 & 21 & 35 \\
\hline & & Self-defense & 12 & 27 & 39 \\
\hline & & Unspecific reply & 19 & 17 & 36 \\
\hline & & Lack of enthusiasm & 10 & 24 & 34 \\
\hline & & Non-verbal avoidance & 10 & 21 & 31 \\
\hline & & Topic switch & 13 & 27 & 40 \\
\hline & & Joke & 27 & 6 & 33 \\
\hline & & Repetition & 14 & 16 & 30 \\
\hline & & Postponement & 18 & 12 & 30 \\
\hline & & Hedge & 11 & 15 & 26 \\
\hline & & Total & 427 & 530 & 957 \\
\hline
\end{tabular}

As Table 6 reveals, for both male and female learners, the most dominant macro function is indirect. That is, both groups of participants were more inclined towards micro strategies related to indirect strategies. With regard to dominant micro function, it was performative verbs for both male learners $(n=44)$ and female learners $(n=68)$. The least used micro strategy for men is excuse $(n=10)$ while for women it is joke $(n=6)$.

\section{CONCLUSION}

Some significant highlights in regards to EFL students are talked about in this examination in that sociocultural standards will have extraordinary impact in transit students perform diverse speech acts. This examination makes ready for additional cross-semantic exploration to see if there is an all inclusive example considering realistic skill or every language has its own particular manner of performing specific speech acts.

It is accepted that this work can be repeated in different settings excessively to affirm the discoveries of the investigation and to show up to new viewpoints. In addition, it will be useful to locate refusal speech act through different instruments like normally happening talk in interactions. Moreover, we can analyze refusal reactions among local English speakers. Force connections ought to be considered as well. For example, one might research whether 
there is any distinction between the manners in which a representative rejects his/her chief or the other way around. The job old enough and social sculptures can't be thought little of also. Age has consistently been a powerful factor particularly in the field of social sciences. Additionally, some longitudinal investigations ought to be done to see if the examples of refusal speech act would change after some time. To place it more or less, refusal speech act is in its earliest stages, in contrast with examines done on other speech acts, for example, saying 'sorry' Subsequently, huge scope examines are expected to discover more data about all inclusive examples of performing refusal speech act.

\section{REFERENCES}

[1] Austin, J. L. (1962). How to do things with words. Oxford: Oxford University Press.

[2] Brown, H. D. (2007). Principles of language learning and teaching. $\left(5^{\text {th }}\right.$ ed.). White Plains, NY: Longman.

[3] Cutting, J. (2002). Pragmatics and discourse: A resource book for students. London and New York. Routledge.

[4] Eslami, Z. R. (2010). How to develop appropriate refusal strategies. In A. Martínez-Flor \& E. Usó-Juan (Eds.), Speech act performance: Theoretical, empirical and methodological issues (pp. 217-236). Amsterdam: John Benjamins.

[5] Ellis, R. (2008). The study of second language acquisition. Oxford: Oxford University Press.

[6] Golato, A. (2003). Studying compliment responses: A comparison of DCTs and recordings of naturally. Applied Linguistics, 24, 90-121.

[7] Ishihara, N., \& Cohen, A. D. (Eds.) (2010). Teaching and learning pragmatics: Where language and culture meet.UK: Pearson Education Limited.

[8] Jalilimehr, M., Pazhakh, A., \& Gorjian, B. (2012). The impact of task variation on request and refusal speech act production in Iranian EFL learners. Journal of Comparative Literature and Culture, 1(1), 1-6.

[9] Kasper, G. (1984). Pragmatic comprehension in learner native speaker discourse.Language Learning, 34(4), 1-20.

[10] Richards, J. C., \& Rodgers, T. (2001). Approaches and methods in language teaching (2nd ed.). New York: Cambridge University Press.

[11] Richards, J. C., \& Schmidt, R. (2002). Dictionary of language teaching \& applied linguistics ( $3^{\text {rd }}$ ed.). Pearson Education: Longman.

[12] Shishavan, H. B., \& Sharifian, F. (2016). The refusal speech act in a cross-cultural perspective: A study of Iranian Englishlanguage learners and Anglo-Australian speakers. Language \& Communication, 47, 75-88.

[13] Stadler, S. A. (2011). Coding speech acts for their degree of explicitness. Journal of Pragmatics, 43, 36-50.

[14] Verschueren, J. (1999). Understanding pragmatics. London: Arnold.

[15] Yule, G. (2006). The study of language ( $3^{\text {rd }}$ ed.). Cambridge: Cambridge University Press.

Bibi Malihe Vamagh Shahi is a PhD candidate of TEFL at the Department of English Language and Literature at Ferdowsi University of Mashhad, Mashhad, Iran. She does research on English language teaching and applied linguistics. She also publishes on second language writing. 